\title{
Anti-oxidant activity of Phenolic Compound Isolated from the Fruits of Acanthopanax sessiliflorus Seeman
}

\author{
Seo-Ji In · Dae-Young Lee $\cdot$ Kyeong-Hwa Seo $\cdot$ Tae-Gyu Nam • \\ Dae-Ok Kim · Geum-Soog Kim • Hyung-Jun Noh • Gye-Won Kim • \\ Woo-Duck Seo $\cdot$ Hee-Cheol Kang • Nam-In Baek*
}

\section{오가피(Acanthopanax sessiliflorus Seeman) 열매로부터 분리한 페놀 화합물의 항산화활성}

인서지 · 이대영 · 서경화 · 남태규 · 김대옥 · 김금숙 · 노형준 ·

김계원 · 서우덕 · 강희철 · 백남인*

Received: 16 October 2012 / Accepted: 4 December 2012 / Published Online: 31 December 2012

(C) The Korean Society for Applied Biological Chemistry 2012

\begin{abstract}
The fruits of Acanthopanax sessiliflorus Seeman (Araliaceae) were extracted with $70 \%$ aqueous ethanol at room temperature. The concentrated extract was partitioned with ethyl acetate (EtOAc), $n$-butyl alcohol, and $\mathrm{H}_{2} \mathrm{O}$, successively. From the EtOAc fraction, two compounds were isolated through the repeated silica gel, octadecyl silica gel, and Sephadex LH-20 column chromatographies. According to the results of physicochemical and spectroscopic data including NMR, mass spectrometry,
\end{abstract}

\section{S.-J. In · K.-H. Seo $\cdot$ N.-I. Baek}

Graduate School of Biotechnology \& Department of Oriental Medicinal Materials and Processing, Kyung Hee University, Yongin 446-701, Republic of Korea

D.-Y. Lee · G.-S. Kim • H.-J. Noh

Herbal Crop Utilization Research Team, National Institute of Horticultural and Herbal Science, RDA, Eumseong 369-873, Republic of Korea

T.-G. Nam • D.-O. Kim

Department of Food Science and Biotechnology, Kyung Hee University, Yongin 446-701, Republic of Korea

\section{G.-W. Kim}

Brewing Research Center, Hankyung National University, Ansung 456749, Republic of Korea

W.-D. Seo

Department of Functional Crop, National Institute of Crop Science, RDA, Milyang 627-830, Republic of Korea

H.-C. Kang

GFC Co., Ltd., Suwon 443-813, Republic of Korea

*Corresponding author (N.-I. Baek: nibaek@khu.ac.kr) and infrared spectroscopy, the chemical structures of the compounds were determined as 3,5-dihydroxycinnamic acid (1) and protocatechuic acid (2). Compound 1 was isolated from the fruits of $A$. sessiliflirus Seeman for the first time. And the compounds were evaluated for the radical scavenging the antioxidant capacity using 2,2'-azino-bis(3-ethylbenzthiazoline-6sulfonic acid)diammonium salt, 1,1-diphenyl-2-picrylhydrazy, and oxygen radical absorbance capacity assay.

Keywords Acanthopanax sessiliflorus $\cdot$ 2,2'-azino-bis(3-ethylbenzthiazoline-6-sulfonic acid)diammonium salt .

3,5-dihydroxycinnamic acid · 1,1-diphenyl-2-picrylhydrazyl ·

NMR $\cdot$ oxygen radical absorbance capacity $\cdot$ protocatechuic acid

서 론

오가피(Acanthopanax sessiliflorus Seeman)는 두릅나무과(Araliaceae) 에 속하는 식물로 낙엽활엽관목이다. 해발 $700 \mathrm{~m}$ 이상의 고산 지대에 자생하는 내건성 및 내한성 식물로, 한국, 일본 북해도, 중국 만주 지역, 러시아의 우수리 지역에 분포하고 있다. 줄기 에는 드물게 큰 가시가 있고, 잎은 호생하며 3 5 소엽으로 된 장상복엽이다. 꽃은 산형화서로 무경 또는 단경이고 과실은 광 타원형으로 9월에 검게 익으며 화주는 합생으로 갈라지지 않는 다(Lee 등, 1996; Ryoo 등, 2003).

오가피는 대한약전에 수재된 생약으로 “오갈피나무 $A$. sessiliflorus Seem. 또는 동속식물(두릅나무과 Araliaceae)의 뿌 
리, 줄기 및 가지의 껍질이다”라고 정의하고 있다. 한방에서는 거풍습(擧風濕), 강근골(强筋骨), 활혈(活血), 보간신(補肝腎) 등 의 효능이 있어 풍한습비(風寒濕痺), 근골경련, 요통, 수종, 경 타박상 등의 치료에 쓰인다(Ryoo 등, 2003). 이러한 오가피의 품종은 동아시아 지역에 약 30 여 종류가 보고되어 있고 그 중 우리나라에는 약 18 종 이상의 다양한 품종이 분포하고 있는 것 으로 알려져 있다. 국내에는 가시오가피(Acanthopanax senticocus Harms), 서울오가피(Acanthopanax seoulense Nakai), 그리고 털 오가피(Acanthopanax rufinerve Nakai) 등이 자생하고 있다 (Yook 등, 1976).

근래에 기능성 식품에 대한 관심의 증가로 유익한 식품들이 다양하게 등장하고 있다. 오가피 연구는 식품학적 측면에서보다 는 약리학적 측면에서 먼저 시작되어 오가피 줄기와 잎으로부 터 stigmasterol, $\beta$-sitosterol 등의 steroid 화합물을 비롯하여 caffeic acid, syringic acid 등의 phenol화합물, syringaresinol, (-)-sesamin, savinin 등의 lignan 화합물, 그리고 sessiloside, chiisanoside 등의 saponin 계열 화합물이 보고되어 있다(Yook 등, 1977; Ryoo 등, 2003; Yoshisumi 등, 2006; Song 등, 2012). 또한 항암, 항당뇨, 혈당 강하, 면역조절, 멜라닌 생성 저 해 등의 활성이 있는 것으로 보고되어 있다(Im 등, 2008; Lim 등, 2010). 오가피의 열매에서는 (-)-sesamin, ursolic acid, hyperin 등이 분리 보고되어 있고, 항암, 면역, 항혈전, 항혈소 판응집 등의 활성이 보고되어 있다(Lee 등, 2002; Lee 등, 2003; Song 등, 2011). 본 연구에서 사용된 오가피 열매(오가자) 는 2009년부터 식약청에 식품으로 등재되어 있으며, 우리나라 전 지역에서 자생 및 재배하여 원료의 확보가 용이하지만, 기 능성 식품으로써의 그 기능과 효능에 대한 연구는 미비한 설정 이다. 따라서 오가피 열매로부터 이차대사산물을 분리 및 동정 하고 그 화합물에 대한 1,1-diphenyl-2-picrylhydrazyl (DPPH), 2,2'-azino-bis(3-ethylbenzthiazoline-6-sulfonic acid)diammonium salt (ABTS), 그리고 oxygen radical absorbance capacity (ORAC) 포획능에 관한 연구를 진행시킴으로써 오가자의 항산화 기능성 식품 또는 의약품 개발 등과 같은 활용방안을 모색하고자 하였다.

\section{재료 및 방법}

실험재료. 본 실험에 사용한 오가피(A. sessiliflorus Seeman) 열 매는 강원도 정선군에서 재배한 것으로 2009년 강원도 정선군 농업기술센터에서 제공 받아 사용하였다. 표본시료(KHU090809) 는 경희대학교 천연물화학실에 보관되어 있다.

시약 및 기기. Column chromatography용 silica gel은 Kiesel gel 60 (Merck, Germany)을, octadecyl silica gel (ODS)은 LiChroprep RP-18 (Merck)을, 그리고 Sephadex LH-20 (Amersham Biosciences, Sweden)를 사용하였다. Thin layer chromatography (이하 TLC라고 함)는 Kieselgel $60 \quad \mathrm{~F}_{254}$ 와 $\mathrm{RP}-18 \mathrm{~F}_{254 \mathrm{~S}}$ (Merck)를 사용하였고, 실험에 이용한 모든 시약은 특급시약을 사용하였다. NMR spectrum은 Varian Inova AS 400 (Varian, USA)으로 측정하였고, infrared spectroscopy (IR) spectrum은 Perkin model 599B (Perkin Elmer, USA)로 측정 하였으며, electron ionization mass spectrometer (EI/MS) spectrum은 JEOL JMS 505-WA (JEOL, Japan)로 측정하였다. UV lamp는 Spectroline (Model ENF-240 C/F, Spectronics Corporation, USA)을 사용하였고, 융점은 Fisher-Johns 융점 측
정기(Fisher Scientific, USA)를 사용하여 측정하였고 미보정하 였다. ABTS, 2,2'-azobis(2-amidino-propane) dihydrochloride $(\mathrm{AAPH})$, 그리고 $\mathrm{DPPH}$ 을 Sigma-Aldrich Co. (USA)에서 구입 하였다.

추출 및 분획. 건조 및 분쇄된 오가자 $10.0 \mathrm{~kg}$ 을 $70 \% \mathrm{EtOH}$ $(50 \mathrm{~L} \times 3)$ 수용액에 담가서 실온에서 추출하였다. 추출물을 여 과하고, 남은 것은 동일한 방법으로 2 회 더 추출하였다. 얻어진 여액을 모두 합쳐 감압 농축하여 $\mathrm{EtOH}$ 추출물 $(2012 \mathrm{~g})$ 을 얻었 다. 얻어진 $\mathrm{EtOH}$ 추출물에 $\mathrm{H}_{2} \mathrm{O}$ 를 $3 \mathrm{~L}$ 가한 후 ethyl acetate (EtOAc) $(4 \mathrm{~L} \times 3)$ 로 분배 추출하였고, 다시 $\mathrm{H}_{2} \mathrm{O}$ 층을 $n$-buthyl alcohol $(n-\mathrm{BuOH})(3.5 \mathrm{~L} \times 3)$ 로 분배 추출하였다. 각 층을 감압 농축하여 EtOAc 분획 $(118 \mathrm{~g}), n-\mathrm{BuOH}$ 분획 $(284 \mathrm{~g})$ 및 $\mathrm{H}_{2} \mathrm{O}$ 분 획 $(1610 \mathrm{~g})$ 을 얻었다.

EtOAc 분획으로부터 페놀 화합물의 분리. EtOAc 분획 $(100 \mathrm{~g})$ 으로부터 silica gel column chromatography (c.c.) $(\varphi 15 \mathrm{~cm} \times$ $20 \mathrm{~cm}, \mathrm{CHCl}_{3}-\mathrm{MeOH}=15: 1 \rightarrow 10: 1 \rightarrow 5: 1 \rightarrow 3: 1 \rightarrow 1: 1 \rightarrow \mathrm{MeOH}$, 각 $2.8 \mathrm{~L}$ )를 실시하여 15 개의 분획물 $(\mathrm{ASFE} 1 \sim \mathrm{ASFE} 15)$ 을 얻었다. 그 중에서 ASFE8 분획 $[8.98 \mathrm{~g}$, elution volume/total volume $(\mathrm{Ve} / \mathrm{Vt})$ $0.67-0.69]$ 을 silica gel c.c. $\left(\varphi 4 \times 12 \mathrm{~cm}, \mathrm{CHCl}_{3}-\mathrm{MeOH}-\mathrm{H}_{2} \mathrm{O}=\right.$ $16: 3: 1(2000 \mathrm{~mL}) \rightarrow 13: 3: 1(1700 \mathrm{~mL}) \rightarrow \mathrm{MeOH}, 3700 \mathrm{~mL}$ 로 하여 9개의 분획(ASFE8-1 ASFE8-9)으로 나누었고 다시 소분획 ASFE8-5 (1.22 g, Ve/Vt 0.59-0.68)에 대하여 Sephadex LH-20 c.c. $\left(\varphi 3 \mathrm{~cm} \times 50 \mathrm{~cm}, \mathrm{MeOH}-\mathrm{H}_{2} \mathrm{O}=4: 1,1800 \mathrm{~mL}\right)$ 를 실시하여 5 개의 분획(ASFE8-5-1 ASFE-8-5-5)으로 나누었다. ASFE-8-5-11 분획 $(104 \mathrm{mg}, \mathrm{Ve} / \mathrm{Vt} \quad 0.80-0.92)$ 에 대하여 ODS c.c. $(\varphi 3 \times 10$, acetone- $\mathrm{H}_{2} \mathrm{O}=1: 2,800 \mathrm{~mL}$ )를 실시하여 화합물 1 (ASFE8-5-11$2,8.0 \mathrm{mg}, \mathrm{Ve} / \mathrm{Vt} 0.22-0.30$, ODS TLC $\mathrm{R}_{\mathrm{f}} 0.60$, acetone- $\mathrm{H}_{2} \mathrm{O}$ $=1: 1)$ 을 분리하였다. $\mathrm{ASFE} 10(6.75 \mathrm{~g}, \mathrm{Ve} / \mathrm{Vt}$ 0.72-0.78)에 대하 여 silica gel c.c. $\left(\varphi 7 \times 15 \mathrm{~cm}, \mathrm{CHCl}_{3}-\mathrm{MeOH}-\mathrm{H}_{2} \mathrm{O}=17: 3: 1\right.$ (1 L) $\rightarrow 15: 3: 1(1 \mathrm{~L}) \rightarrow 13: 3: 1(1.2 \mathrm{~L}) \rightarrow \mathrm{MeOH}, 3.2 \mathrm{~L})$ 를 실시하여 10 개 의 분획(ASFE-10-1 ASFE-10-10)으로 나누었고, 다시 소분획 ASFE-10-8 (800 mg, $\mathrm{Ve} / \mathrm{Vt}$ 0.75-0.88)에 대하여 Sephadex $\mathrm{LH}-20$ c.c. $\left(\varphi 3 \mathrm{~cm} \times 50 \mathrm{~cm}, \mathrm{MeOH}-\mathrm{H}_{2} \mathrm{O}=5: 1,1600 \mathrm{~mL}\right)$ 를 실 시하여 화합물 2 (ASFE10-8-10, $15.0 \mathrm{mg}, \mathrm{Ve} / \mathrm{Vt} \quad 0.55-0.60$, ODS TLC $\left.\mathrm{R}_{\mathrm{f}} 0.50, \mathrm{MeOH}-\mathrm{H}_{2} \mathrm{O}=1: 1\right)$ 를 분리하였다.

화합물 1 White amorphous powder $(\mathrm{MeOH})$; m.p. 242$244^{\circ} \mathrm{C}$; EI/MS m/z $180 \quad[\mathrm{M}]^{+}$; IR $v_{\max }\left(\mathrm{CaF}_{2}\right.$ plate $)$ 3675, 1683, 1600, 1518, 1391, 1259, 1117; ${ }^{1} \mathrm{H}-\mathrm{NMR}$ (400 MHz, pyridine- $\left.d_{5}, \delta_{\mathrm{H}}\right) 8.12(1 \mathrm{H}, \mathrm{d}, J=15.6 \mathrm{~Hz}, \mathrm{H}-7), 7.62(1 \mathrm{H}, \mathrm{s}$, H-4), 7.20 (2H, s, H-2, 6), $6.82(1 \mathrm{H}, \mathrm{d}, J=15.6 \mathrm{~Hz}, \mathrm{H}-8)$; ${ }^{13} \mathrm{C}-\mathrm{NMR} \quad\left(100 \mathrm{MHz}\right.$, pyridine- $\left.d_{5}, \delta_{\mathrm{C}}\right) 169.60$ (C-9), 149.85 (C-3), 147.67 (C-5), 145.16 (C-7), 127.32 (C-1), 121.79 (C2), 116.94 (C-6), 116.77 (C-4), 115.76 (C-8).

화합물 2 White amorphous powder $(\mathrm{MeOH})$; m.p. 178-180 ${ }^{\circ} \mathrm{C}$; EI/MS m/z $154[\mathrm{M}]^{+}$; IR $v_{\max }\left(\mathrm{KBr}, \mathrm{cm}^{-1}\right)$ 3450, 1710, 1640, 1550, 1040; ${ }^{1} \mathrm{H}-\mathrm{NMR}\left(400 \mathrm{MHz}\right.$, pyridine- $\left.d_{5}, \delta_{\mathrm{H}}\right) 8.39$ $(1 \mathrm{H}, \mathrm{d}, J=2.4 \mathrm{~Hz}, \mathrm{H}-2), 8.11(1 \mathrm{H}, \mathrm{d}, J=8.0 \mathrm{~Hz} \mathrm{H}-5), 7.34$ $(1 \mathrm{H}, \mathrm{dd}, J=8.0,2.4 \mathrm{~Hz}, \mathrm{H}-6) ;{ }^{13} \mathrm{C}-\mathrm{NMR}(100 \mathrm{MHz}$, pyridine$\left.d_{5}, \quad \delta_{\mathrm{C}}\right) \quad 169.60 \quad(\mathrm{C}-7), 151.97 \quad(\mathrm{C}-4), 147.01 \quad(\mathrm{C}-3), 123.86$ (C-1), 123.28 (C-2), 118.28 (C-6), 116.14 (C-5).

항산화능 측정. $\mathrm{ABTS}$ 법을 이용한 각 시료의 항산화능은 $\mathrm{ABTS}$ radical을 이용하여 측정하였다(Kim 등, 2003). $1.0 \mathrm{mM}$ $\mathrm{AAPH}$ 에 $2.5 \mathrm{mM}$ ABTS와 phosphate buffered saline (PBS) 용액 $100 \mathrm{~mL}$ 를 섞어서 $70^{\circ} \mathrm{C}$ 항온수조에서 30 분간 반응시켜 


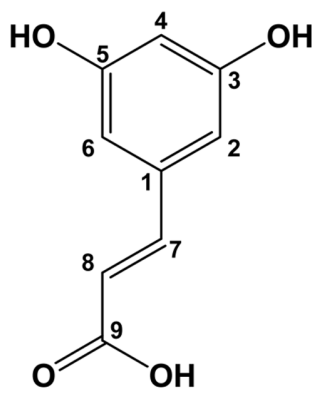

1

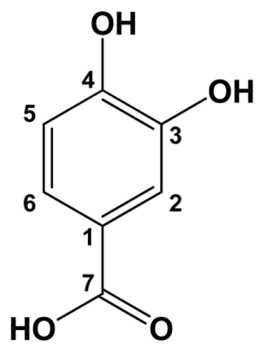

2
Fig. 1 Chemical structures of phenolic compounds from the fruits of Acanthopanax sessiliflorus.

ABTS radical용액을 만들고 완충용액인 PBS 용액을 이용하여 $734 \mathrm{~nm}$ 에서 $0.650 \pm 0.020$ 의 흡광도가 되도록 ABTS radical용액 을 희석하였다. ABTS radical용액 $980 \mu \mathrm{L}$ 와 시료 $20 \mu \mathrm{L}$ 를 10 분간 반응 후 $37^{\circ} \mathrm{C}$ 에서 $734 \mathrm{~nm}$ 에 흡광도가 감소된 정도를 측 정하였다. 두 페놀 화합물에 대한 항산화능은 $\mathrm{mg}$ vitamin $\mathrm{C}$ equivalents (VCE) $\cdot \mathrm{g}^{-1}$ dry weight로 나타내었다. DPPH radical 소거능 실험은 Brand-Wiliams 등(1995)의 방법을 변형하여 측 정하였다. $80 \%$ 메탄올을 사용하여 $100 \mu \mathrm{M}$ 의 DPPH radical 용 액을 제조 한 후에, 이 DPPH radical 용액을 $80 \%$ 메탄올을 이용하여 $517 \mathrm{~nm}$ 에서 $0.650 \pm 0.020$ 의 흡광도가 되도록 희석하 였다. 각 시료 $50 \mu \mathrm{L}$ 와 $\mathrm{DPPH}$ radical 용액 $2.95 \mathrm{~mL}$ 을 첨가하 여 $23^{\circ} \mathrm{C}$ 에서 30 분간 빛이 차단된 장소에서 반응시킨 후 $\mathrm{DPPH}$ radical 감소량을 $517 \mathrm{~nm}$ 에서 측정하였다. $\mathrm{DPPH}$ radical 소거능 을 통한 두 페놀 화합물에 대한 항산화능은 $\mathrm{g} \mathrm{VCE} \cdot \mathrm{g}^{-1}$ 로 나 타내었다. ORAC assay는 Huang 등(2002)의 방법을 이용하여 측정하였다. Free radical generater (AAPH)를 혼합하고 열을 가함으로써 발생하는 fluorescent의 산화적 감소를 측정하였다. 각 화합물 $25 \mu \mathrm{L}$ 와 fluorescein 용액 $(81.6 \mathrm{nM}) 150 \mu \mathrm{L}$ 를 96 well plate에 첨가한 후 3 분 동안 흔들어 주고 $37^{\circ} \mathrm{C}$ 에서 10 분 간 반응시켰다. 그 후에 $25 \mu \mathrm{L} \mathrm{AAPH}(153 \mathrm{mM})$ 를 혼합하여 fluorometer (Tecan infinite M200, Tecan, USA)를 fluorometer 를 사용하여 $485 \mathrm{~nm}$ 에서 전자가 여기(ex-citation)되고 $520 \mathrm{~nm}$ 에 서 방출(emission)되게 측정하였고 결과는 $\mathrm{mg} \mathrm{VCE} \cdot \mathrm{g}^{-1} \mathrm{dry}$ weight로 나타내었다.

\section{결과 및 고찰}

오가자를 $70 \% \mathrm{EtOH}$ 로 추출하여 얻어진 추출물에 대하여 용매 의 극성에 따라 EtOAc, $n-\mathrm{BuOH}$ 및 $\mathrm{H}_{2} \mathrm{O}$ 로 순차 분획하고 각 분획을 감압 농축하여 3 개의 분획을 얻었다. EtOAc 분획으로 부터 silica gel, ODS 및 Sephadex LH-20 column chromatography 를 반복 실시하여, 2종의 화합물을 분리하였다.

화합물 1 (White amorphous powder)은 EI/MS에서 $\mathrm{m} / \mathrm{z}$ $180[\mathrm{M}]^{+}$의 분자이온 peak가 관측되어 분자량을 180 으로 결정 하였다. IR 스펙트럼으로부터 수산기 $\left(3675 \mathrm{~cm}^{-1}\right)$, 공역 carbonyl 기 $\left(1683 \mathrm{~cm}^{-1}\right)$, 그리고 이중결합 $\left(1600 \mathrm{~cm}^{-1}\right)$ 의 작용기를 갖는 것 으로 확인되었다. ${ }^{1} \mathrm{H}-\mathrm{NMR}\left(400 \mathrm{MHz}\right.$, pyridine- $\left.d_{5}\right)$ spectrum에 서 olefine methine proton signal $\left[\delta_{\mathrm{H}} 8.12(1 \mathrm{H}, \mathrm{d}, J=15.6\right.$
Table 1 Antioxidant capacity of phenolic compounds from the fruits of A. sessiliflorus.

\begin{tabular}{lccr}
\hline & \multicolumn{3}{c}{ Antioxidant capacity (g VCE/g) } \\
\cline { 2 - 4 } & ABTS & DPPH & ORAC \\
\hline 3,5-dihydroxycinnamic acid (1) & $2.98 \pm 0.20$ & $2.03 \pm 0.17$ & $11.21 \pm 1.57$ \\
\hline protocatechuic acid (2) & $2.19 \pm 0.14$ & $1.87 \pm 0.18$ & $3.85 \pm 0.33$ \\
\hline
\end{tabular}

$\mathrm{Hz}, \mathrm{H}-7), 6.82(1 \mathrm{H}, \mathrm{d}, J=15.6 \mathrm{~Hz}, \mathrm{H}-8)]$ 2개가 관측되어 trans 구조를 갖는 이중결합 한 쌍의 존재가 확인되었으며, olefine methine proton signal $[7.62(1 \mathrm{H}, \mathrm{s}, \mathrm{H}-4), 7.20(2 \mathrm{H}$, $\mathrm{s}, \mathrm{H}-2,6)] 3$ 개가 관측되어 $1,3,5$-삼치환 벤젠고리를 갖는 화합 물로 추정할 수 있었다. ${ }^{13} \mathrm{C}-\mathrm{NMR}(100 \mathrm{MHz})$ spectrum에서 9 개의 탄소가 관측되어 phenylpropanoid 골격의 화합물로 확인 되었다. 1 개의 carbonyl carbon signal $\left[\left(\delta_{\mathrm{C}} 169.60\right.\right.$ (C-7) $]$ 과 2 개의 oxygenated olefine quaternary carbon signal $\left[\delta_{\mathrm{C}} 149.85\right.$ (C-3), 147.67 (C-5)], 5개의 olefin methine carbon signal $\left[\delta_{\mathrm{C}}\right.$ 145.16 (C-7), 121.79 (C-2), 116.94 (C-6), 116.77 (C-4), 115.76 (C-8)] 그리고 1 개의 olefin quaternary carbon signal $\left[\left(\delta_{\mathrm{C}}\right.\right.$ $127.32(\mathrm{C}-1))]$ 이 관측되었다. 이를 종합하여 본 결과, trans 배 향 $\left(J_{7,8}=15.6 \mathrm{~Hz}\right)$ 의 이중결합을 포함하고 있고 벤젠고리와 carboxyl기를 가진 탄소 수 9개의 phenyl propanoid 골격의 화 합물임을 알 수 있었다. 이를 종합한 결과, 화합물 1은 3,5dihydroxycinnamic acid로 동정하였다.

화합물 2 (White amorphous powder)는 EI/MS에서 $\mathrm{m} / \mathrm{z} 154$ $[\mathrm{M}]^{+}$의 분자이온 peak가 관측되어 분자량을 154 로 결정하였다. IR 스펙트럼으로부터 수산기 $\left(3320 \mathrm{~cm}^{-1}\right)$, 공역 carbonyl기(1666 $\left.\mathrm{cm}^{-1}\right)$ 및 이중결합 $\left(1640 \mathrm{~cm}^{-1}\right)$ 의 작용기를 갖는 것으로 확인되 었다. ${ }^{1} \mathrm{H}-\mathrm{NMR}\left(400 \mathrm{MHz}\right.$, pyridine- $d_{5}$ ) spectrum에서 3 개의 olefine methine proton signal $\left[\delta_{\mathrm{H}} 8.39(1 \mathrm{H}, \mathrm{d}, J=2.4 \mathrm{~Hz} \mathrm{H}-\right.$ 2), $8.11(1 \mathrm{H}, \mathrm{d}, J=8.0 \mathrm{~Hz} \mathrm{H}-5), 7.34(1 \mathrm{H}, \mathrm{dd}, J=8.0,2.4$ $\mathrm{Hz}, \mathrm{H}-6)]$ 이 관측되어 이 화합물을 1,2,4-삼치환 벤젠고리를 갖 는 화합물로 추정하였다. ${ }^{13} \mathrm{C}-\mathrm{NMR}\left(100 \mathrm{MHz}\right.$, pyridine- $\left.d_{5}\right)$ spectrum에서 7 개의 탄소 signal이 관측되었다. $\delta_{\mathrm{C}} 169.78$ 에서 carboxyl carbon signal 1 개와, oxygenated olefine quaternary carbon signal $\left[\delta_{\mathrm{C}} 151.97(\mathrm{C}-4), 147.01\right.$ (C-3)] 2개, olefine quaternary carbon signal $\left[\delta_{\mathrm{C}} 123.86(\mathrm{C}-1)\right] 1$ 개, 그리고 olefine methine carbon signal $\left[\delta_{\mathrm{C}} 123.28\right.$ (C-2), 118.28 (C6), 116.14 (C-5)] 3개가 관측되었다. 이를 종합하여 1,2,4-삼치 환 벤젠고리에 carboxyl기가 결합된 화합물임을 알 수 있었다. 이를 토대로 문헌과 비교하여, 화합물 $\mathbf{2}$ 를 protocatechuic acid 로 동정하였다(Lee 등, 2011). 화합물 1은 이번에 오가자에서는 처음으로 분리되었다.

두 페놀 화합물의 항산화능은 ABTS radical, DPPH radical 및 $\mathrm{ORAC}$ assay법을 적용하여 검토하였으며 결과는 Table 1과 같다. $\mathrm{ABTS}$ 와 $\mathrm{DPPH}$ 는 비교적 안정한 free radical로서 항산화 활성 검정에 많이 이용되고 있다. ABTS radical 소거능을 평가 한 결과 화합물 1 은 $2.98 \pm 0.20 \mathrm{~g} \mathrm{VCE} / \mathrm{g}$ 의 항산화능을 보였고, 화합물 2는 $2.19 \pm 0.14 \mathrm{~g} \mathrm{VCE} / \mathrm{g}$ 의 항산화능을 나타냈다. $\mathrm{DPPH}$ radical 소거능에 대한 평가도 유사하게 나타났는데 화합물 1은 $2.03 \pm 0.17 \mathrm{~g} \mathrm{VCE} / \mathrm{g}$ 의 항산화능을 보였고 화합물 2는 $1.87 \pm$ $0.18 \mathrm{~g} \mathrm{VCE} / \mathrm{g}$ 의 항산화능을 보였다. $\mathrm{AAPH}$ 에 의한 peroxy radical의 생성과 소멸에 따른 fluorescent의 감소율을 ORAC assay에 의해 측정한 결과, 화합물 $\mathbf{1}$ 과 화합물 $\mathbf{2}$ 는 각각 11.21 
$\pm 1.57 \mathrm{~g} \mathrm{VCE} / \mathrm{g}, 3.85 \pm 0.33 \mathrm{~g} \mathrm{VCE} / \mathrm{g}$ 으로 높은 항산화능을 보 였다. 화합물 모두 잘 알려진 항산화 물질인 vitamin $\mathrm{C}$ 보다 약 2 배 이상으로 나타났고, ORAC에서는 화합물 1은 11배, 화합물 2는 3 배로 높은 결과가 나타났다.

오가자로부터 분리된 페놀 화합물에 대한 문헌을 조사해 본 결과 3,5-dihydroxycinnamic acid (1)에 대한 활성에 관련된 문 헌은 찾을 수 없었고, protocatechuic acid (2)는 항산화 활성을 가지고 있으며 그 외에 항균, 항염증 활성, 그리고 세포독성 등 을 나타내는 것으로 보고 되어있다(Li 등, 2011; Nawal 등, 2011; Yagi 등, 2012).

앞으로 이들 화합물들에 대한 다양한 생리적 및 약리적 활성 을 검토함으로써 기능성 식품, 화장품 또는 의약품의 소재로서 충분한 가치가 있다고 여겨지며, 추후 이의 활용과 관련된 연 구를 추진하고자 한다.

\section{초 록}

오가피(Acanthopanax sessiliflorus Seeman) 열매를 실온에서 $70 \%$ ethanol $(\mathrm{EtOH})$ 로 추출하고 이 추출물을 ethyl acetate (EtOAc) 분획, $n$-butyl alcohol 분획, $\mathrm{H}_{2} \mathrm{O}$ 분획으로 나누었다. EtOAc 분획에 대하여 silica gel, octadecyl silica gel 및 Sephadex LH-20 column chromatography를 반복 실시하여 2종 의 화합물을 분리, 정제하였다. NMR, infrared spectroscopy, 및 electron ionization/mass spectrometry 등의 spectrum을 해석하 여, 화합물 1과 화합물 2를 각각 3,5-dihydroxycinnamic acid과 protocatechuic acid 로 구조를 결정하였다. 화합물 1은 오가자 에서는 처음으로 분리된 화합물이다. 또한 이 화합물에 대한 2,2'-azino-bis(3-ethylbenzthiazoline-6-sulfonic acid)diammonium salt, 1,1-diphenyl-2-picrylhydrazyl 및 oxygen radical absorbance capacity radical 소거능을 이용한 항산화 활성을 측정하였는데, 모두 vitamin $\mathrm{C}$ 보다 2배 이상 활성이 높은 것으로 나타났다.

Keywords 오가피·2,2'-azino-bis(3-ethylbenzthiazoline-6sulfonic acid) diammonium salt $\cdot 3,5$-dihydroxycinnamic acid 1,1-diphenyl-2-picrylhydrazyl $\cdot \mathrm{NMR} \cdot$ oxygen radical absorbance capacity $\cdot$ protocatechuic acid

감사의 글 본 연구는 2012년도 농촌진흥청(국립원예특작과학원) 박사 후 연수과정 지원사업(PJ008465)에 및 차세대 바이오그린 21 사업(과제번호 PJ008020)으로 수행되었으며 지원에 감사드립니다.

\section{참고문헌}

Brand-Willians W, Cuvelier ME, and Berset C (1995) Use of a free radical method to evaluate antioxidant activity. LWT-Food Technol 28, 25-30.

Huang D, Ou B, Hampsch-Woodill M, Flanagan J, and Prior RL (2002) Highthroughput assay of oxygen radical absorbance capacity (ORAC) using a multichannel liquid handling system coupled with a microplate fluorescence reader in 96-well format. $J$ Agric Food Chem 20, 4437-4.

Im KR, Kim MJ, Jung TK, and Yoon KS (2008) The inhibitory effects of Acanthopanax sessiliflorum Seeman on melanogenesis. J Soc Cosmet Scientists Korea 34, 149-56.

Kim DO, Jeong SW, and Lee CY (2003) Antioxidant capacity of phenolic phytochemicals from various cultivars of plums. Food Chem 81, 321-6.

Lee IC, Bae JS, Kim TW, Kwon OJ, and Kim TH (2011) Polyphenolic constituents from the aerial parts of Thymus quinquecostatus var. japonica collected on Ulleung island. J Korean Soc Appl Biol Chem 54, $811-6$.

Lee SH, Kim BK, Cho SH, and Shin KH (2002) Phytochemical constituents from the fruits of Acanthopanax sessiliflorus. Arch Pharm Res 25, 2804.

Lee SH, Lee YS, Jung SH, Ji J, Shin KH, Kim BK, and Kang SS (2003) Antitumor and immunostimulating activities of Acanthopanax sessiliflorus fruits. Nat Prod Sci 9, 112-6.

Lee WT (1996) In Lineamenta Florae Korea (vol. 770). Academy Co, Seoul, Korea.

Li XC, Wang XZ, Chen, DF, and Chen SZ (2011) Antioxidant activity and mechanism of protocatechuic acid in vitro. Functional Foods in Health and Disease 1, 232-44.

Lim SH, Park, YH, Kwon CJ, Ham HJ, Jeong HN, Kim KH et al. (2010) Anti-diabetic and hypoglycemic effect of Eleutherococcus spp. J Korean Soc Food Sci Nutr 39, 1761-8.

Nawal AM, Shagufta P, Itrat F, Muhammad N, and Ajaz H (2011) Antioxidant, anti-glycation and anti-inflammatory activities of phenolic constituents from Cordia sinensis. Molecules 16, 10214-26.

Ryoo HS, Park SY, Chang SY, and Yook CS (2003) Triterpene components from the leaves of Acanthopanax sessiliflorus Seem. Korean $J$ Pharmacogn 34, 269-73.

Song Y, Deng Y, Huang D, Wen J, Liu Z, and Li FM (2012) LC-MS/MS determination and pharmacokinetic study of four lignan components in rat plasma after oral administration of Acanthopanax sessiliflorus extract. $J$ Ethnopharmacol 141, 957-63.

Song Y, Yang CJ, Yu K, and Li FM (2011) In vivo antithrombotic and antiplatelet activities of a quantified Acanthopanax sessiliflorus fruit extract. Chinese J Natural Medicines 9, 141-5.

Yagi S, Chretien F, Duval RD, Fontanay S, Maldini M, Piacente S et al. (2012) Antibacterial activity, cytotoxicity and chemical constituents of Hydnora johannis roots. South Afr J Bot 78, 228-34.

Yook CS, Lee DH, and Seo YK (1976) A new forma of Acanthpanax sepcies (I). Korean J Pharmacogn 7, 179-90.

Yook CS, Lee DH, Seo YK, and Ryu KS (1977) Study on the constituents in the root bark of Acanthopanax sessiliflorum Seemann (II). Korena $J$ Pharmacogn 8, 31-4.

Yoshisumi K, Hirano K, Ando H, Hirai Y, Ida Y, Tsuji TJ et al. (2006) Lupane-type saponins from leaves of Acanthopanax sessiliflorus and their inhibitory activity on pancreatic lipase. $J$ Agric Food Chem 54, $335-41$. 